\title{
Report on a New Opioid NPS: Chemical and In Vitro Functional Characterization of a Structural Isomer of the MT-45 Derivative Diphenpipenol
}

\author{
Annelies Cannaert $\mathbb{1}^{1, \dagger}+$, Fabian Hulpia $\mathbb{D}^{2, \dagger}$, Martijn Risseeuw $\mathbb{D}^{2}$, \\ Katleen Van Uytfanghe $\mathbb{1}^{1}$, Eric Deconinck ${ }^{3}$, Serge Van Calenbergh $\mathbb{D}^{2}$, \\ Peter Blanckaert ${ }^{4}{ }^{4}$ and Christophe Stove ${ }^{1}{ }^{1, *}$
}

\begin{abstract}
${ }^{1}$ Laboratory of Toxicology, Department of Bioanalysis, Faculty of Pharmaceutical Sciences, Ghent University, Ottergemsesteenweg 460, 9000 Ghent, Belgium, ${ }^{2}$ Laboratory for Medicinal Chemistry, Department of Pharmaceutics, Faculty of Pharmaceutical Sciences, Ghent University, Ottergemsesteenweg 460, 9000 Ghent, Belgium, ${ }^{3}$ Section of Medicines and Health Products, Scientific Direction Chemical and Physical Health Risks, Sciensano, Juliette Wytsmanstraat 14, 9050 Brussels, Belgium, and ${ }^{4}$ Belgian Early Warning System Drugs, Substance Use and Related Disorders, Sciensano, Juliette Wytsmanstraat 14, 9050 Brussels, Belgium
\end{abstract}

\footnotetext{
*Author to whom correspondence should be addressed. Email: christophe.stove@ugent.be

†Equally contributed.
}

\begin{abstract}
In this paper, the identification and full characterization of a novel non-fentanyl opioid sourced online, which is a member of the 1-substituted-4-(1,2-diphenylethyl)piperazine derivatives related to MT-45, is reported. The sample was sold under the name "diphenpipenol," (3-[2-[4-(2-methoxyphenyl)piperazin-1-yl]-2-phenylethyl]phenol), although extensive NMR analysis showed that the product obtained was actually a diphenpipenol structural isomer, (2-[4-(2methoxyphenyl)piperazin-1-yl]-1,2-diphenylethanol). Liquid chromatography time-of-flight mass spectrometry identified an exact mass for the protonated molecule of $\mathrm{m} / \mathrm{z} 389.2264$, with two prominent fragment ions ( $\mathrm{m} / \mathrm{z} 91.0567$ and 150.0937), which were not reported in earlier literature describing MT-45 derivatives. The chemical characterization was finalized by gas chromatographymass spectrometry, high-performance liquid chromatography diode array detector and Fouriertransform infrared spectroscopy analyses. This product is a clear example of the trend that new non-fentanyl opioids are reappearing on the recreational drug market to escape the recent changes in (inter)national legislation concerning fentanyl analogues. Although in this particular case, the product's potency and efficacy were relatively low, other new non-fentanyl opioids might possess stronger potencies and therefore pose greater health risks for ignorant users. The fact that the product was sold under the wrong name further demonstrates the well-known problematic issue of a mismatch between the adverted and true identity, confirming the irregularities of the online new psychoactive substances market.
\end{abstract}




\section{Introduction}

In the last decade, there has been a progressive increase in the number of new psychoactive substances (NPS). These substances comprise a wide variety of drugs, such as synthetic cannabinoids, stimulants, benzodiazepines and opioids. Synthetic opioids are narcotic analgesics, and some of them are widely used in human medicine, but they can also lead to abuse and may produce dependence. While currently playing a relatively small role in the NPS market, many new opioids are highly potent substances that can pose a serious threat to individual and public health $(1,2)$.

From 2009 to 2018, 49 new synthetic opioids have been detected on Europe's drug market (1). The majority $(n=34)$ of these are fentanyl derivatives. Their popularity can be explained by their relatively simple synthesis in addition to excellent online precursor availability (3). More recently, the implementation of new national and international legislation has resulted in a shift, away from the fentanyl-type opioids, toward synthetic opioids from the "others" category (examples include 2F-viminol, 2-Me-AP-237, isotonitazene, U-47700) (4-6).

This paper reports on the identification and full characterization of a novel non-fentanyl opioid sourced online: 2-[4-(2methoxyphenyl)piperazin-1-yl]-1,2-diphenylethanol, a structural isomer of diphenpipenol (3-[2-[4-(2-methoxyphenyl)piperazin-1-yl]-2phenylethyl]phenol), an NPS opioid and member of the 1-substituted4-(1,2-diphenylethyl)piperazine derivatives related to MT-45 (Figure 1). MT-45 (1-cyclohexyl-4-(1,2-diphenylethyl)piperazine) is a synthetic opioid investigated as an analgesic in the 1970s (7-9) which has reappeared on the recreational drug market in 2013 (10). Since 2016, MT-45 is listed in Schedule I of the 1961 Convention (11, 12). Interestingly, the product sourced online was wrongly sold under the name diphenpipenol, which is a structural analogue of MT-45. While it has been reported that MT-45 has a comparable analgesic potency to morphine in animal models, diphenpipenol showed a much stronger effect (up to 105 times compared to morphine for the most potent $S$-enantiomer) $(7,13)$. Extensive NMR analysis showed that the product obtained was a structural isomer of diphenpipenol (the difference lies in the position of the hydroxyl group, Figure 1). This isomer has up to now only been mentioned once in literature (14), and no information on the potency of this compound has been reported before.

\section{Materials and Methods}

\section{Materials}

All reagents used during the analyses were at least of HPLC grade. For NMR analysis, deuterated dimethyl sulfoxide (DMSO$\mathrm{d}_{6}, 99.8 \%$ ) was purchased from Eurisotop (Saint-Aubin, FR). Hydromorphone was purchased as hydromorphone $\mathrm{HCl}$ from Fagron (Nazareth, Belgium). Fentanyl was obtained as a free base from LGC Chemicals (Wesel, Germany). MT-45 was a kind gift from Prof. Volker Auwärter and was originally purchased from Cayman Chemical Company (Ann Arbor, MI, USA). Dulbecco's Modified Eagle's Medium (DMEM; GlutaMAX ${ }^{\mathrm{TM}}$ ), Opti-MEM $^{\circledR}$ I Reduced Serum Medium, Penicillin-Streptomycin $(5.000 \mathrm{U} / \mathrm{mL})$ and amphotericin B $(250 \mu \mathrm{g} / \mathrm{mL})$ were purchased from Thermo Fisher Scientific (Pittsburg, PA, USA). Fetal bovine serum (FBS) and poly-D-lysine were supplied by Sigma Aldrich (Overijse, Belgium). The Nano-Glo ${ }^{\circledR}$ Live Cell reagent, which was used for the readout of the bioassay, was procured from Promega (Madison, WI, USA).

\section{Sample preparation}

The sample (a white homogenous powder), sold as diphenpipenol, was obtained during routine online monitoring of drug markets, performed continuously in the framework of the functioning of the Belgian Early Warning System Drugs (BEWSD). It was provided in a clear plastic unmarked ziplock bag, which was sealed in an aluminum pouch, unmarked as well. It was used, as provided, after short-term storage in the freezer (range minus $20^{\circ} \mathrm{C}$-minus $30^{\circ} \mathrm{C}$ ) for analysis. For all the chromatographic analyses and the determination of the biological activity, $5.15 \mathrm{mg}$ of the powder was dissolved in $0.5 \mathrm{~mL}$ of methanol as a stock solution. For NMR analysis, a sample $(9.0 \mathrm{mg})$ was dissolved in DMSO- $\mathrm{d}_{6}(\sim 0.75 \mathrm{~mL})$. For the optical rotation analysis, a sample $(9.0 \mathrm{mg})$ was dissolved in $2.0 \mathrm{~mL} \mathrm{MeOH}$.

\section{Instrumentation}

Liquid chromatography time-of-flight mass spectrometry, gas chromatography-mass spectrometry and high-performance liquid chromatography diode array detector

For liquid chromatography time-of-flight mass spectrometry (LC-QTOF-MS), chromatographic separation was accomplished with an Agilent 1290 Infinity LC system and a Phenomenex Kinetex C18-column $(2.6 \mu \mathrm{m}, 3 \times 50 \mathrm{~mm})$, maintained at $30^{\circ} \mathrm{C}$. The highresolution mass spectrometry (HRMS) system was a 5600+ QTOF from Sciex, with an electrospray ionization (ESI) source and Analyst TF 1.7.1 software, from the same provider. The LC-HRMS analysis was performed using the same settings as those described $(5,15)$, obtaining a TOF-MS full scan combined with a data-dependent acquisition of product ion spectra. For gas chromatography-mass spectrometry (GC-MS), one $\mu \mathrm{L}$ of a $1 / 10$ dilution of the stock solution was injected on an Agilent 7890A GC system (Agilent HP-5MS column, $30 \mathrm{~m} \times 0.25 \mathrm{~mm}$ i.d. $\times 0.25 \mu \mathrm{m}$ ) coupled to a $5975 \mathrm{XL}$ mass-selective detector operated by MSD Chemstation software, as has been described (5). For the HPLC-DAD (high-performance liquid chromatography diode array detector), reversed-phase separation was performed on a LaChrom HPLC system from Merck-Hitachi (Tokyo, Japan), using a Merck Purospher ${ }^{\circledR}$ Star RP-8 endcapped column $(5 \mu \mathrm{m}, 125 \mathrm{~mm} \times 4.6 \mathrm{~mm})$ fitted with a Merck Purospher ${ }^{\circledR}$ Star RP-8 endcapped guard column ( $5 \mu \mathrm{m}, 4 \mathrm{~mm} \times 4 \mathrm{~mm})$, as has been described (5). Detection was done by a diode array detector (DAD), monitoring a wavelength from 220 to $350 \mathrm{~nm}$ with a slit of $1 \mathrm{~nm}$, a spectral bandwidth of $1 \mathrm{~nm}$ and a spectral interval of $200 \mathrm{~ms}$, as described before (5).

\section{Fourier-transform infrared spectroscopy analysis}

Fourier-transform infrared spectroscopy (FT-IR) spectra were recorded using a Nicolet iS10 FT-IR spectrometer (Thermo Fisher Scientific, Waltham, USA), equipped with a Smart iTR accessory and a deuterated triglycine sulphate detector. The infrared spectrum was subsequently recorded from 4000 to $400 \mathrm{~cm}^{-1}$ with a spectral resolution of $4 \mathrm{~cm}^{-1}$ and 32 co-added scans. Spectral data were obtained using the OMNIC Software version 8.3 (Thermo Fisher Scientific, Madison, USA) as described before (5).

\section{Nuclear magnetic resonance spectroscopy (NMR)}

NMR measurements were performed on a Bruker Avance ${ }^{\circledR}$ Neo $(400 \mathrm{MHz})$ spectrometer, operated at room temperature $\left(25^{\circ} \mathrm{C}\right)$. Chemical shifts $(\delta)$ are reported in ppm, and spectra are referenced to the residual solvent peak signal. Coupling constants are given in Hz. Copies of the relevant ${ }^{1} \mathrm{H}-,{ }^{13} \mathrm{C}-\mathrm{NMR}$ and $2 \mathrm{D}$ NMR spectra are included in the Supplementary Data. 


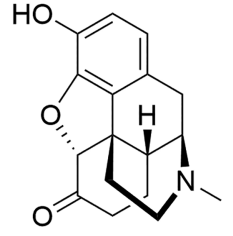

Hydromorphone<smiles>CCC(=O)N(c1ccccc1)C1CCN(CCc2ccccc2)CC1</smiles>

Fentanyl<smiles>c1ccc(C[C](c2ccccc2)N2CCN(C3CCCCC3)CC2)cc1</smiles>

MT-45<smiles>COc1ccccc1N1CCN([C@@H](Cc2cccc(O)c2)c2ccccc2)CC1</smiles>

Diphenpipenol

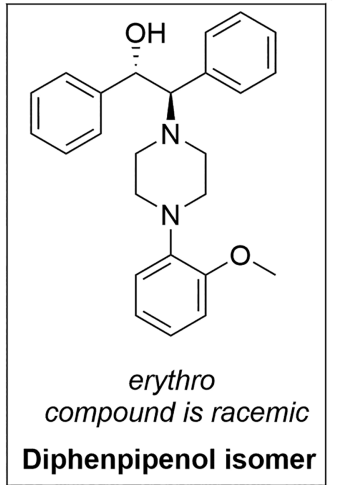

Figure 1. Chemical structure of hydromorphone, fentanyl, MT-45, diphenpipenol and the structural isomer that was sourced online.

\section{Optical rotation}

Optical rotation $\left(\alpha_{D}^{20}\right)$ was performed on a Perkin Elmer 241 Polarimeter, employing a cell of $10.001 \mathrm{~cm}$.

\section{Determination of in vitro biological activity at the $\mu$-opioid} receptor

A live cell-based reporter assay that monitors the $\mu$-opioid receptor activation via its interaction with $\beta$-arrestin- 2 using the NanoLuc Binary Technology was applied to assess the biological activity of the powder $(5,16,17)$. The cells were routinely maintained at $37^{\circ} \mathrm{C}$, $5 \% \mathrm{CO}_{2}$, under humidified atmosphere in DMEM (GlutaMAX ${ }^{\mathrm{TM}}$ ) supplemented with $10 \%$ heat-inactivated FBS, $100 \mathrm{IU} / \mathrm{mL}$ penicillin, $100 \mathrm{mg} / \mathrm{L}$ streptomycin and $0.25 \mathrm{mg} / \mathrm{L}$ amphotericin B. The day prior to the experiments, cells were seeded on white poly-D-lysinecoated 96-well plates at $5 \times 10^{4}$ cells/well and incubated overnight. The cells were washed twice with Opti-MEM ${ }^{\circledR}$ I Reduced Serum Medium to remove any remaining FBS, and $90 \mu \mathrm{L}$ Opti-MEM ${ }^{\circledR}$ I and $25 \mu \mathrm{L}$ of the Nano-Glo ${ }^{\circledR}$ Live Cell reagent were added to each well. Subsequently, the plate was placed into a TriStar ${ }^{2}$ LB 942 multimode microplate reader (Berthold Technologies GmbH \& Co., Germany). Luminescence was monitored during the equilibration period until the signal stabilized ( $15 \mathrm{~min})$. Next, $20 \mu \mathrm{L}$ per well of test compounds present as concentrated $(6.75$-fold, as $20 \mu \mathrm{L}$ was added to generate a final volume of $135 \mu \mathrm{L}$ ) stock solutions in Opti-MEM ${ }^{\circledR}$ I was added. The luminescence was continuously monitored for $120 \mathrm{~min}$. Solvent controls were included in all experiments. The results are represented as mean area under the curve (AUC) \pm standard error of mean (SEM), obtained in three independent experiments. All results were normalized to the $E_{\max }$ of hydromorphone $(=100 \%)$, our reference compound. Curve fitting of concentration-response curves via nonlinear regression (four-parameter logistic fit) was employed to determine $\mathrm{EC}_{50}$ (a measure of potency) and the $E_{\max }$ (a measure of efficacy) using GraphPad Prism software (San Diego, CA, USA).

\section{Results}

\section{LC-QTOF-MS, GC-MS, HPLC-DAD and FT-IR analysis}

QTOF-MS in the full scan mode revealed a peak with an exact mass $m / z$ value of 389.2264. Calculating the elemental composition, assuming a single protonation of the molecule, resulted in a $4.05 \mathrm{ppm}$ error for the molecular formula of diphenpipenol $\left(\mathrm{C}_{25} \mathrm{H}_{28} \mathrm{~N}_{2} \mathrm{O}_{2}\right)$. The obtained product ion spectrum is shown in Figure 2A. Five major product ions were observed, with an $\mathrm{m} / \mathrm{z}$ value of $91,105,150$,
193 and 197. Most of these fragments, as well as the less abundant fragments, match with those proposed for MT-45 and its derivatives, as found in literature $(18,19)$. The $m / z$ value 197 corresponds to the hydroxylated diphenylethane moiety, although only the structural isomer can produce further fragmentation down to $m / z 91$ and 105 (or at lesser extent to $m / z 77$ and 119, see Figure 2A)). The $\mathrm{m} / \mathrm{z}$ fragment of 193 matches the methoxyphenylpiperazine moiety (which fragments further into $\mathrm{m} / \mathrm{z} 150$ ). The latter fragment of $\mathrm{m} / \mathrm{z}$ 150 was not found in the MT-45 spectra and could only be found in MT-45 analogues with a methoxyphenylpiperazine moiety (20-22).

Using the LC-QTOF-MS method, the compound had a retention time of $6.03 \mathrm{~min}$ (the LC-QTOF chromatogram is shown in Supplementary Figure S1). GC-MS analysis revealed only one peak with a retention time of $25.4 \mathrm{~min}$ (GC-MS spectrum in Figure $2 \mathrm{~B}$ ). The spectrum of the only peak (retention time $20.59 \mathrm{~min}$ ) obtained with the HPLC-DAD method is shown in Figure 2C. The compound had two absorption maxima, at 235.7 and $277.2 \mathrm{~nm}$. No major impurities were found via any of the applied chromatographic methodologies.

The FT-IR spectrum of the sample was recorded using attenuated total reflectance. The obtained spectrum was matched against an in-house library, but no match could be obtained. Next to the signal of the aromatic rings at wavenumber 1491.51 (between 1450 and 1650), the presence of the hydroxyl group on the aromatic ring could clearly be demonstrated with the characteristic peak at wavenumber 1216.80 (between 1180 and 1260), as well as the aromatic ether with characteristic bands at wavenumbers 1041.77 and 1237.53 (double band between 1020-1075 and 1200-1275) (Figure 2D).

\section{NMR analysis and optical rotation}

${ }^{1} \mathrm{H}-\mathrm{NMR}$ and ${ }^{13} \mathrm{C}-\mathrm{NMR}$ analysis was performed to confirm the structure of diphenpipenol (Figure 3A and B; Supplementary Figures S2-S8), which revealed the presence of 28 protons, consistent with diphenpipenol. Additionally, the presence of a small, probably structurally related impurity (Figure $3 \mathrm{~A}$ ) was noted, as well as a peak at $\delta=2.38 \mathrm{ppm}$, which could not be related to the structure of the main compound (2D NMR spectra, Supplementary Figures S9-S21). It was suspected that the latter signal originates from the presence of a dimethylamine salt.

The structure of diphenpipenol could not be confirmed due to two observations in the ${ }^{1} \mathrm{H}$ NMR spectrum: (1) the aromatic region integrates for $14 \mathrm{H}(5+9)$, instead of $13 \mathrm{H}$ expected for diphenpipenol, (2) the presence of a doublet at $\delta=5.67 \mathrm{ppm}(1 \mathrm{H})$ and doublet of doublets at $\delta=4.72 \mathrm{ppm}(1 \mathrm{H})$, which is inconsistent with the 

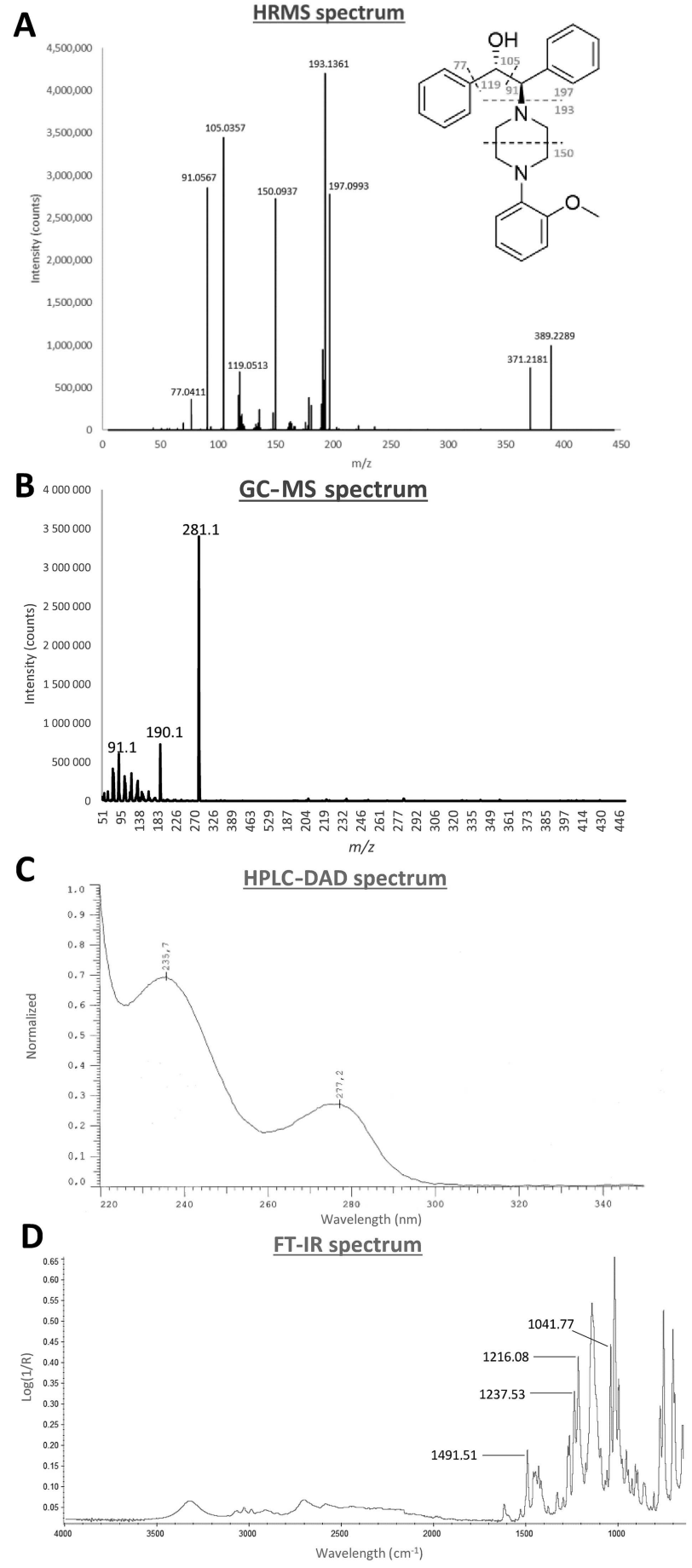

Figure 2. (A) HR-MS fragment ion spectrum after infusion, with proposed fragments; (B) electron ionization spectrum obtained via GC-MS; (C) HPLCDAD spectrum and (D) FT-IR spectrum of the sample, recorded in ATR mode with indication of the characteristic bands for the aromatic groups, the aromatic hydroxyl group and the aromatic ether.

presence of a benzylic methylene. The integration, splitting pattern and number of protons do not match with a diphenylethylamine system as present in diphenpipenol. The latter observation matches with the presence of four methylene units in the ${ }^{1} \mathrm{H}_{-}{ }^{13} \mathrm{C}$ HSQC spectrum (Supplementary Figures S11-S13), instead of the expected five for diphenpipenol.
Exact mass measurements were used to compute a derived DBE (double bond equivalent) number, which indicated a structure with 13 DBE. The aromatic region of the ${ }^{1} \mathrm{H}-\mathrm{NMR}$ spectrum contains $14 \mathrm{H}$, indicating the presence of two monosubstituted $(2 \times 5 \mathrm{H})$ and one disubstituted phenyl ring, accounting for 12 DBE. The last DBE is most likely a fourth ring system in the molecule as no evidence was found to indicate the presence of olefinic protons.

Next, a suite of 2D NMR experiments was employed to establish the connectivity pattern of the molecule (Supplementary Figures S9S21). 2D ${ }^{1} \mathrm{H}^{-1} \mathrm{H}$ COSY analysis (Supplementary Figures S9-S10) revealed the presence of three isolated spin systems (not including the aromatic region), comprised of (1) the exchangeable proton at $\delta=9.82 \mathrm{ppm}, \delta=5.67 \mathrm{ppm}$ and $\delta=4.72 \mathrm{ppm}$; two sets of two methylene groups, (2) $\delta=4.08 \mathrm{ppm}, \delta=3.63 \mathrm{ppm}, \delta=3.15 \mathrm{ppm}$ and $\delta=2.93 \mathrm{ppm}$; and (3) $\delta=3.68 \mathrm{ppm}, \delta=3.37 \mathrm{ppm}$ and $\delta=3.20$, $3.04 \mathrm{ppm}$. These three spin systems, together with the need for another ring system (one DBE to be accounted for) in the molecule, as well as the presence of only four quaternary carbons (DEPT, Supplementary Figure S8), point toward a piperazine ring system. Thus, it was concluded that the compound, sold as diphenpipenol, appears to be a constitutional isomer with a diarylethanol system on one side of the piperazine ring and a third phenyl ring on the other side. This is in full agreement with the observed fragmentation pattern obtained via QTOF-MS.

Then, the position of the methoxy group was determined by means of ${ }^{1} \mathrm{H}_{-}{ }^{13} \mathrm{C}$ HSQC, ${ }^{1} \mathrm{H}_{-}-{ }^{13} \mathrm{C} \mathrm{HMBC}$ and ${ }^{1} \mathrm{H}_{-}{ }^{1} \mathrm{H} 2 \mathrm{D}$ NOESY (Supplementary Figures S11-S20). Firstly, the $\mathrm{OCH}_{3}$ group is attached to an aromatic ring because of (1) the presence of $14 \mathrm{H}$ in the ${ }^{1} \mathrm{H}-\mathrm{NMR}$ spectrum and (2) a quaternary carbon at $\delta=151.9 \mathrm{ppm}$ (confirmed by a cross peak in ${ }^{1} \mathrm{H}_{-}{ }^{13} \mathrm{C} \mathrm{HMBC}$ ). Next, the relative position of the methoxy group on the phenyl ring was determined as ortho, inferred from several observations: a para-substituted phenyl ring would give rise to a symmetrically substituted ring with the orthoand meta-carbon atoms being equivalent, which would be apparent in the ${ }^{1} \mathrm{H}^{13} \mathrm{C}$ HSQC spectrum. Para-substitution is thus excluded as four carbon/hydrogen cross peaks $(\delta=112.0 \mathrm{ppm}, \delta=118.2 \mathrm{ppm}$, $\delta=120.9 \mathrm{ppm}, \delta=123.5 \mathrm{ppm})$ are observed. Continuing, the presence of two strong and one weak ${ }^{1} \mathrm{H}^{-13} \mathrm{C}$ HMBC cross-peak (Supplementary Figures S14-S16) with the quaternary carbon at $\delta=151.9 \mathrm{ppm}$ is indicative of ortho-substitution, further corroborated by a cross-peak in the 2D NOESY spectrum between $\mathrm{OCH}_{3}$ and $\mathrm{H} 3$ of the substituted phenyl ring. From these observations, it could be concluded that the methoxy substituent is at the ortho-position relative to the second substituent in the disubstituted phenyl ring.

Finally, the position of the methoxy-substituted phenyl ring in the molecule was investigated by $2 \mathrm{D}^{1} \mathrm{H}_{-}{ }^{1} \mathrm{H}$ NOESY (Supplementary Figures $\mathrm{S} 17-\mathrm{S} 20)$. The proton attached to $\mathrm{C}_{\mathrm{PheOCH}}(\delta=6.95 \mathrm{ppm})$ shows four cross-peaks with methylene protons, belonging to the two spin systems making up the piperazine ring. A clear separation between two sets of protons was noted; one set showed cross-peaks with the methine protons and the other set with $\mathrm{H}_{6} \mathrm{PheOCH}_{3}$. This observation indicates that the disubstituted phenyl ring and the methine protons are on opposite sides of the piperazine ring, rather than the disubstituted phenyl ring being attached to either methine carbon atom, all of which is in accordance with the fragmentation pattern observed via QTOF-MS.

Next, relative stereochemistry of the diphenpipenol constitutional isomer was determined to be erythro (Figure 1), based on the observed (small) coupling constant $\left({ }^{3} J=3.2 \mathrm{~Hz}\right)$ between the two methine protons (23). A full account supporting this assignment is given in the Supporting information (Supplementary Figure S22). 
A
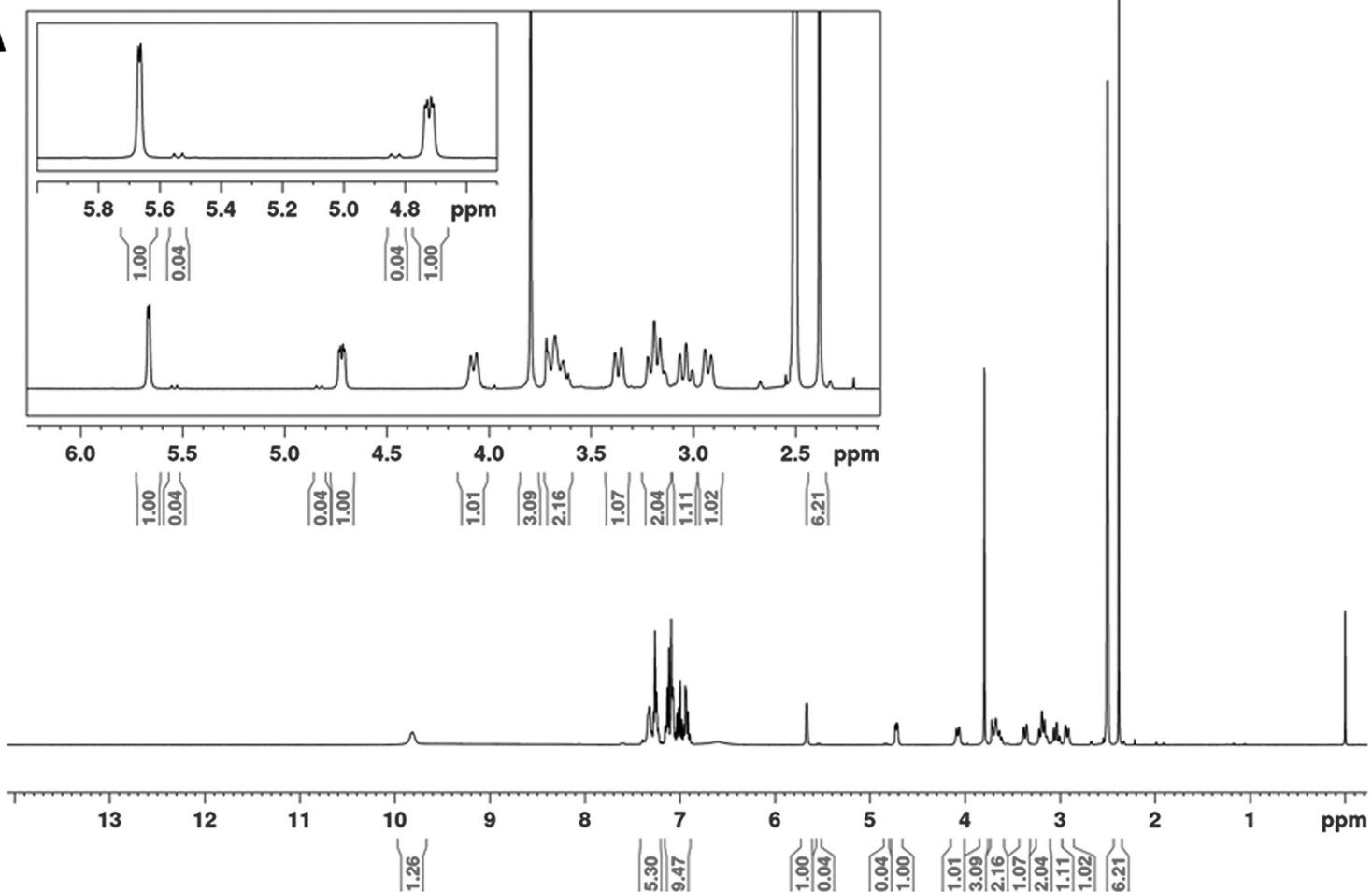

B
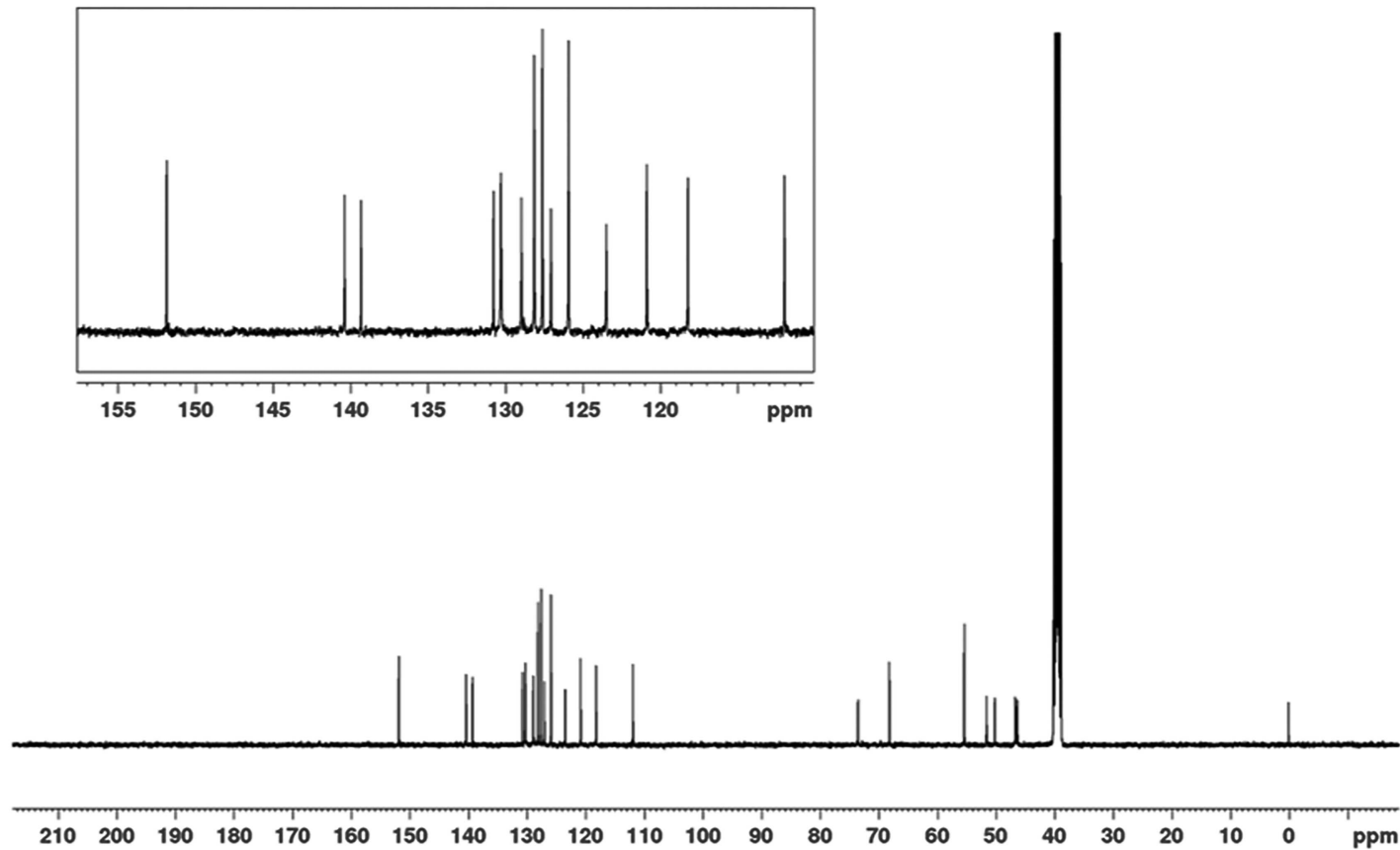

Figure 3. (A) ${ }^{1} \mathrm{H}$ NMR spectrum. ${ }^{1} \mathrm{H}$ NMR $\left(400 \mathrm{MHz}\right.$, DMSO- $\left.\mathrm{d}_{6}\right) \delta: 2.93(\mathrm{~d}, J=11.2 \mathrm{~Hz}, 1 \mathrm{H}), 3.04(\mathrm{t}, J=11.8 \mathrm{~Hz}, 1 \mathrm{H}), 3.14-3.22(\mathrm{~m}, 2 \mathrm{H}), 3.37(\mathrm{~d}, J=12.4 \mathrm{~Hz}, 1 \mathrm{H})$, 3.61-3.72 (m, 2H), $3.80\left(\mathrm{~m}, 3 \mathrm{H}, \mathrm{OCH}_{3}\right), 4.08(\mathrm{~d}, J=11.3 \mathrm{~Hz}, 1 \mathrm{H}), 4.72(\mathrm{dd}, J=8.3,3.1 \mathrm{~Hz}, 1 \mathrm{H}, \mathrm{CHOH}), 5.67(\mathrm{~d}, J=3.2 \mathrm{~Hz}, 1 \mathrm{H}, \mathrm{CHN}), 6.90-7.15(\mathrm{~m}, 9 \mathrm{H}), 7.22-7.40$ $(\mathrm{m}, 5 \mathrm{H}), 9.82(\mathrm{~d}, J=7.6 \mathrm{~Hz}, 1 \mathrm{H})$. (B) ${ }^{13} \mathrm{C}$ NMR spectrum. ${ }^{13} \mathrm{C}$ NMR (101 MHz, DMSO-d 6 ) $8: 46.4,46.7,50.2,51.6,55.4\left(\mathrm{OCH}_{3}\right), 68.2,73.5,112.0\left(\mathrm{C} 3_{\mathrm{PheOCH}}\right), 118.2$

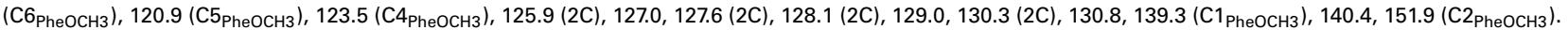




\section{$\%$ MOR activation (relative to HM)}

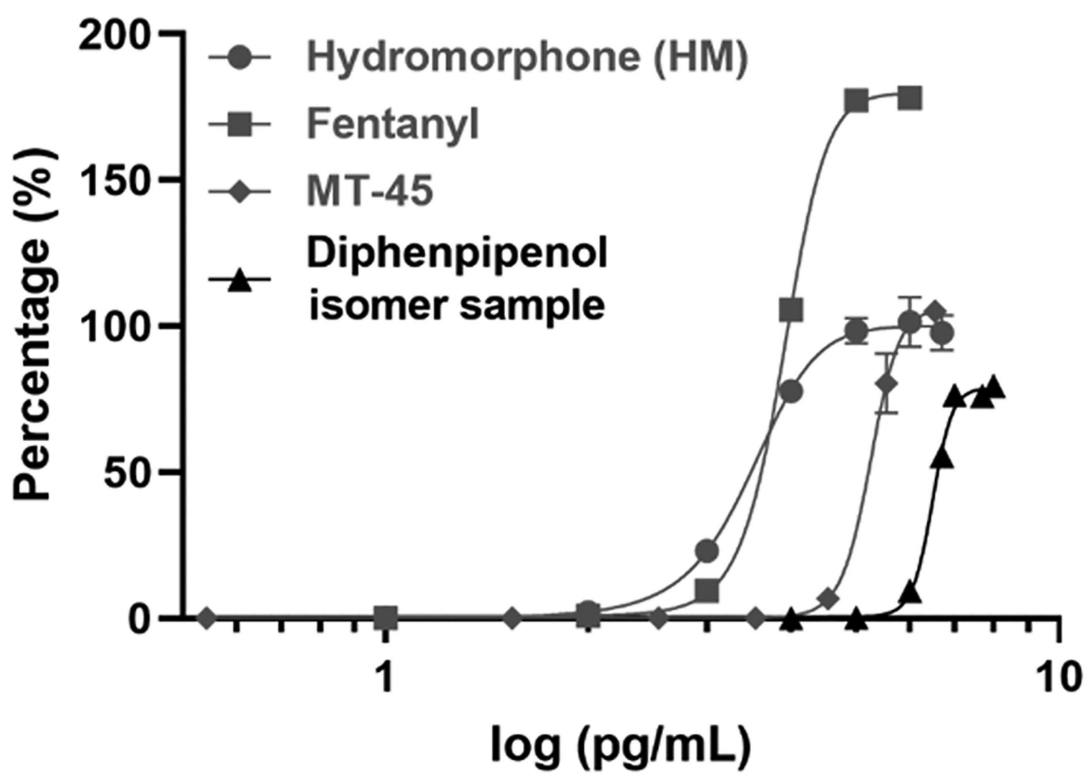

\begin{tabular}{|lccc|} 
& $\mathrm{EC}_{50}(\mathrm{ng} / \mathrm{mL})$ & $\mathrm{EC}_{50}(\mathrm{nM})$ & $\mathrm{E}_{\max }(\%)$ \\
\hline HM & $3.06(1.98-4.75)$ & $10.7(6.94-16.6)$ & $100(94.3-106)$ \\
\hline Fentanyl & $7.87(6.95-8.78)$ & $23.4(20.7-26.1)$ & $180(175-185)$ \\
\hline MT-45 & $181(120-271)$ & $520(343-779)$ & $114(103-125)$ \\
\hline $\begin{array}{l}\text { Diphenpipenol } \\
\text { isomer sample }\end{array}$ & $\begin{array}{c}3.05 \times 10^{3} \\
\left(2.41 \times 10^{3}-3.93 \times 10^{3}\right)\end{array}$ & - & $78.7(74.5-83.0)$ \\
\hline
\end{tabular}

Figure 4. Concentration-dependent interaction of the $\mu$-opioid receptor with $\beta$-arrestin-2 upon stimulation with hydromorphone (HM), fentanyl, MT-45 and the powder sample sourced online. Data are given as mean receptor activation $\pm \operatorname{SEM}(n=3)$, normalized to the $E_{\max }$ of $\mathrm{HM}(=100 \%)$. The $\mathrm{EC}_{50}$ and $E_{\max }$ values are presented as a measure of potency and efficacy, respectively, given as $\mathrm{EC}_{50} / E_{\max }$ values $(95 \% \mathrm{Cl}$ profile likelihood).

Finally, in order to establish the absolute stereochemistry, polarimetry was employed. Optical rotation measurements gave a rotation of $0.00^{\circ}$, indicative of a racemic mixture.

Determination of in vitro biological activity at the $\mu$-opioid receptor

As there was no reference material available and no absolute certainty on the purity of the powder (presence of dimethylamine salt), the in vitro activity was determined on the sample itself (expressed in mass instead of molar) and compared to hydromorphone, fentanyl and MT-45 (Figure 4). The powder showed only a poor potency at the $\mu$-opioid receptor compared to hydromorphone and fentanyl $\left(\mathrm{EC}_{50}\right.$ values of $3045 \mathrm{ng} / \mathrm{mL}$ (95\% CI: 2410-3933) vs. $3.06 \mathrm{ng} / \mathrm{mL}$ (95\% CI: $1.98-4.75)$ and $7.87 \mathrm{ng} / \mathrm{mL}$ (95\% CI: 6.95-8.78), respectively). Only at very high concentrations a similar efficacy $\left(E_{\max }\right.$ of $78.7 \%$ ) was obtained. The structural analogue MT-45 also showed a relatively weak potency at the $\mu$-opioid receptor $(181 \mathrm{ng} / \mathrm{mL}$ (95\% CI: 120-271)) compared to hydromorphone and fentanyl. The latter finding is not surprising as MT-45 was reported to have a higher selectivity toward the $\delta$ - and $\kappa$-opioid receptors $(11,12,24,25)$. As the different analyses showed no major impurities in the powder sourced online, it was concluded that the diphenpipenol isomer does not have a profound activity at the $\mu$-opioid receptor, although any activity at the other opioid receptors cannot be excluded.

\section{Discussion}

In this paper, the identification and full characterization of a novel non-fentanyl opioid sourced online which is member of the 1-substituted-4-(1,2-diphenylethyl)piperazine derivatives related to MT-45 were reported. The sample was sold under the name "diphenpipenol" although extensive NMR analysis showed that the product obtained is a structural isomer of diphenpipenol (2-[4-(2methoxyphenyl)piperazin-1-yl]-1,2-diphenylethanol). This product is a clear example of the trend that new non-fentanyl opioids are reappearing on the recreational drug market to escape the recent changes in (inter)national legislation concerning fentanyl analogues. Although in this particular case the product's potency and efficacy were relatively low, other new non-fentanyl opioids might possess stronger potencies and therefore pose greater health risks for ignorant users. The fact that the product was sold under the wrong name further demonstrates the well-known problematic issue 
of a mismatch between the adverted and true identity, confirming the irregularities of the online NPS market.

\section{Supplementary Data}

Supplementary data is available at Journal of Analytical Toxicology online.

\section{Author Contributions}

A.C. executed the biological evaluation and wrote the manuscript together with F.H. F.H. and M.R. performed the NMR analyses. The LC-QTOF, GC-MS and HPLC-DAD analyses were done by K.V.U. E.D. did the FTIR analysis. P.B. provided the product. S.V.C. and C.S. contributed to the writing of the manuscript.

\section{Funding}

A.C. acknowledges funding as a postdoctoral research fellow from the Research Foundation-Flanders (FWO; 12Y9520N) and the Ghent University-Special Research Fund (BOF; PDO026-18). The latter is also acknowledged by C.S. (grants no. 01 N00814 and 01 J15517). S.V.C. thanks the Hercules Foundation (project AUGE/17/22 "Pharm-NMR") for funding.

\section{References}

1. EMCDDA European Drug Report 2019: Trends and Developments. European Monitoring Centre for Drugs and Drug Addiction: Lisbon, 2019.

2. Jannetto, P.J., Helander, A., Garg, U., Janis, G.C., Goldberger, B. (2019) The fentanyl epidemic and evolution of fentanyl analogs in the United States and the European Union. Clinical Chemistry, 65, 242-253.

3. Sharma, K.K., Hales, T.G., Rao, V.J., NicDaeid, N., McKenzie, C. (2019) The search for the "next" euphoric non-fentanil novel synthetic opioids on the illicit drugs market: current status and horizon scanning. Forensic Toxicology, 37, 1-16.

4. Bao, Y., Meng, S., Shi, J., Lu, L. (2019) Control of fentanylrelated substances in China. The Lancet. Psychiatry, 6, e15. doi: 10.1016/S2215-0366(19)30218-4.

5. Blanckaert, P., Cannaert, A., Van Uytfanghe, K., Hulpia, F., Deconinck, E., Van Calenbergh, S., et al. (2019) Report on a novel emerging class of highly potent benzimidazole NPS opioids: chemical and in vitro functional characterization of isotonitazene. Drug Testing and Analysis, 12, 422-430. doi: 10.1002/dta.2738.

6. Krotulski, A.J., Papsun, D.M., Kacinko, S.L., Logan, B.K. (2020) Isotonitazene quantitation and metabolite discovery in authentic forensic casework. Journal of Analytical Toxicology. doi: https://doi.org/10.1093/jat/bkaa016.

7. Natsuka, K., Nakamura, H., Uno, H., Umemoto, S. (1975) Studies on 1-substituted 4-(1,2-diphenylethyl)piperazine derivatives and their analgesic activities. 1'. Journal of Medicinal Chemistry, 18, 1240-1244.

8. Hakuri Nishimura, I., Hitoshi Uno, T., Kagayaki Natsuka, I., Noriaki Shimokawa, N., Massanao Shimizu, K., Hideo Nakamura, T. 1-substituted-4-(1,2-diphenylethyl)-piperazine derivatives and compositions containing the same, 1978; United States Patent.

9. Hakuri Nishimura, I., Hitoshi Uno, T., Kagayaki Natsuka, I., Noriaki Shimokawa, N., Massanao Shimizu, K., Hideo Nakamura, T. 1-substituted-4-(1,2-diphenylethyl)-piperazine derivatives and compositions containing the same, 1979; United States Patent.

10. Helander, A., Backberg, M., Beck, O. (2014) MT-45, a new psychoactive substance associated with hearing loss and unconsciousness. Clinical Toxicology (Philadelphia, PA), 52, 901-904.

11. EMCDDA Report on the Risk Assessment of MT-45 in the Framework of the Council Decision on New Psychoactive Substances. European Monitoring Centre for Drugs and Drug Addiction: Lisbon, 2014.

12. WHO MT-45: Critical Review Report. World Health Organization, 2015.

13. Natsuka, K., Nakamura, H., Nishikawa, Y., Negoro, T., Uno, H., Nishimura, H. (1987) Synthesis and structure-activity relationships of 1-substituted 4-(1,2-diphenylethyl)piperazine derivatives having narcotic agonist and antagonist activity. Journal of Medicinal Chemistry, 30, 1779-1787.

14. Shimokawa, N., Nakamura, H., Shimakawa, K., Minami, H., Nishimura, H. (1979) Studies on analgesic agents. 1.1a preparation of 1,2-diphenyl2-(4-substituted 1-piperazinyl)ethanol derivatives and structure-activity relationships. Journal of Medicinal Chemistry, 22, 58-63.

15. Thoren, K.L., Colby, J.M., Shugarts, S.B., Alan, H.B.W., Lynch, K.L. (2016) Comparison of information-dependent acquisition on a tandem quadrupole TOF vs a triple quadrupole linear ion trap mass spectrometer for broad-Spectrum drug screening. Clinical Chemistry, 62, 170-178.

16. Cannaert, A., Vasudevan, L., Friscia, M., Mohr, A.L.A., Wille, S.M.R., Stove, C.P. (2018) Activity-based concept to screen biological matrices for opiates and (synthetic) opioids. Clinical Chemistry, 64, 1221-1229.

17. Cannaert, A., Ambach, L., Blanckaert, P., Stove, C.P. (2018) Activitybased detection and bioanalytical confirmation of a fatal carfentanil intoxication. Frontiers in Pharmacology, 9, 486.

18. McKenzie, C., Sutcliffe, O.B., Read, K.D., Scullion, P., Epemolu, O., Fletcher, D., et al. (2018) Chemical synthesis, characterisation and in vitro and in vivo metabolism of the synthetic opioid MT-45 and its newly identified fluorinated analogue 2F-MT-45 with metabolite confirmation in urine samples from known drug users. Forensic Toxicology, 36, 359-374.

19. Montesano, C., Vannutelli, G., Fanti, F., Vincenti, F., Gregori, A., Rita Togna, A., et al. (2017) Identification of MT-45 metabolites: in silico prediction, in vitro incubation with rat hepatocytes and in vivo confirmation. Journal of Analytical Toxicology, 41, 688-697.

20. Stojanovska, N., Kelly, T., Tahtouh, M., Beavis, A., Fu, S. (2014) Analysis of amphetamine-type substances and piperazine analogues using desorption electrospray ionisation mass spectrometry. Rapid Communications in Mass Spectrometry, 28, 731-740.

21. Meyer, M.R., Holderbaum, A., Kavanagh, P., Maurer, H.H. (2015) Low resolution and high resolution MS for studies on the metabolism and toxicological detection of the new psychoactive substance methoxypiperamide (MeOP). Journal of Mass Spectrometry, 50, 1163-1174.

22. Sloczynska, K., Panczyk, K., Waszkielewicz, A.M., Marona, H., Pekala, E. (2016) In vitro mutagenic, antimutagenic, and antioxidant activities evaluation and biotransformation of some bioactive 4-substituted 1-(2methoxyphenyl)piperazine derivatives. Journal of Biochemical and Molecular Toxicology, 30, 593-601.

23. Munk, M.E., Meilahn, M.K., Franklin, P. (1968) Conformational equilibria in the 2-amino-1,2-diphenylethanol system I. Nuclear magnetic resonance studies. The Journal of Organic Chemistry, 33, 3480-3486.

24. Fujimura, H., Tsurumi, K., Nozaki, M., Hori, M., Imai, E. (1978) Analgesic activity and opiate receptor binding of 1-cyclohexyl-4(1,2-diphenylethyl)piperazine. Japanese journal of pharmacology, 28, 505-506.

25. Nozaki, M., Niwa, M., Imai, E., Hori, M., Fujimura, H. (1983) 1,2Diphenylethyl piperazines as potent opiate-like analgesics; the unusual relationships between stereoselectivity and affinity to opioid receptor. Life sciences, 33, 431-434. 